\title{
RESPOSTA DA APLICAÇÃO DO 1-MCP EM FRUTOS DE MAMOEIRO 'GOLDEN' EM DIFERENTES ESTÁDIOS DE MATURAÇÃ̃ ${ }^{1}$
}

\author{
MAXIMILIANO SILVA DE SOUZA², INGA GONÇALVES DE AZEVEDO, \\ SÁVIO FIGUEIRA CORRÊA ${ }^{4}$, MARCELO GOMES DA SILVA ${ }^{5}$, \\ MESSIAS GONZAGA PEREIRA ${ }^{6}$, JURANDI GONÇALVES DE OLIVEIRA ${ }^{7}$
}

RESUMO - O estudo de fatores que influenciam no processo de amadurecimento é fundamental para o planejamento do processo de comercialização, principalmente em frutos com padrão de respiração climatérico e perecível, como é o caso do mamão. Nesse trabalho, avaliou-se o efeito da aplicação do 1-MCP (1-metilciclopropeno) sobre o amadurecimento de frutos de mamoeiro nos estádios $0 ; 1$ e 2 de maturação. O 1-MCP diminui a produção de etileno ( $\approx 79 \%$ ) e a taxa respiratória ( $\approx 45 \%)$, principalmente em frutos no estádio 0 de maturação. $\mathrm{O}$ uso deste inibidor da ação do etileno retardou a perda de coloração verde da casca dos frutos, principalmente em frutos nos estádios 0 e 1 de maturação. Houve redução na perda de firmeza do fruto e do mesocarpo nos estádios 1 e 2. Entretanto, em frutos no estádio 0 de maturação, a firmeza do mesocarpo manteve-se alta, o que pode comprometer a aceitação destes frutos pelo consumidor. $\mathrm{O}$ teor de sólidos solúveis não foi influenciado pela aplicação do 1-MCP. O efeito do 1-MCP na redução da atividade das enzimas PME e PG foi maior em frutos nos estádios 0 e 1 de maturação em comparação a frutos no estádio 2 de maturação. A atividade da PME demonstrou crescente aumento ao longo do período de armazenamento, porém a atividade da PG permaneceu baixa ao longo dos cinco primeiros dias, com aumento posterior. Os resultados mostraram que a PME exerce influência significativa na perda de firmeza da polpa nos primeiros dias, com atuação posterior da PG. O 1-MCP mostrou-se eficiente em retardar o processo de amadurecimento de frutos de mamoeiro, tornando-se mais eficiente quando associado a estádios de maturação iniciais.

Termos para indexação: etileno, poligalacturonase, pectinametilesterase.

\section{RESPONSES OF 1-MCP APPLICATIONS IN 'GOLDEN' PAPAYA FRUITS ON DIFFERENTS MATURATION STAGES}

\begin{abstract}
The study of factors that influence the process of ripening is critical for planning the marketing process, mainly in standard breathing climacteric and perishing fruits, as it is the case of papaya. In this work it was evaluated the effect of the application of 1-MCP (1- methylcyclopropene) in the pattern of fruit ripening of papaya at the maturation stages 0,1 and 2. The 1-MCP delayed the production of ethylene $(\approx 79 \%)$ and the respiratory rate $(\approx 45 \%)$ mainly in fruit maturation stages 0 . The use of the inhibitor of the ethylene action delayed the degreening of the fruits, especially in fruit maturation stages 0 and 1 . With 1-MCP application there was a reduction in loss of flesh and fruit firmness in stages 1 and 2. However, in fruit maturation stage 0 , the flesh firmness showed excessively high, which may decrease the acceptance for consumer of these fruits. The solid soluble content was not influenced by the application of the 1-MCP. The effect of 1-MCP in the reduction of the activity of the enzymes PME and PG was bigger in fruit maturation stages 0 and 1 than fruit maturation stage 2. The PME enzyme activity demonstrated an increasing over the shelf life; however, the PG enzyme activity remained low during the first five days of shelf life, increasing later. The results showed that the PME enzyme exerts significant influence on loss of flesh firmness, and the PG acting later. The 1-MCP was effective delaying the process of ripening of papaya fruits being more efficient when associated with initial maturation stages.
\end{abstract}

Index terms: ethylene, polygalacturonase, pectinmethylesterase

\footnotetext{
${ }^{1}$ (Trabalho 202-08). Recebido em: 04-08-2008. Aceito para publicação em: 23-06-2009.

${ }^{2}$ Mestre em Produção Vegetal, Escola Técnica Estadual Agrícola Antonio Sarlo - Rede FAETEC, Campos dos Goytacazes-RJ, maxbj@uenf.br; ${ }^{3}$ Doutoranda em Biociências e Biotecnologia, Universidade Estadual do Norte Fluminense - UENF, Campos dos Goytacazes-RJ, inga@uenf.br;

${ }^{4}$ Doutorando em Ciências Naturais, UENF, Campos dos Goytacazes-RJ, savio@uenf.br.

${ }^{5}$ Dr. rer Nat., UENF, Campos dos Goytacazes-RJ, mgs@uenf.br.

${ }^{6} \mathrm{PhD}$ Genética e Melhoramento, UENF, Campos dos Goytacazes-RJ, messias@uenf.br.

${ }^{7}$ Dr. Biologia Vegetal, UENF, Avenida Alberto Lamego, 2000. Sala 20 e 21 anexo CCTA. CEP.: 28013-602, Campos dos Goytacazes - RJ, jugo@uenf.br. autor para correspondência.
} 


\section{INTRODUÇÃO}

O Brasil destaca-se como um grande produtor de mamão (Martins \& Costa, 2003). A cultura está distribuída na maioria dos Estados brasileiros, sendo os Estados da Bahia e do Espírito Santo os produtores mais importantes, respondendo por $87,9 \%$ desta produção. O Estado do Espírito Santo é o segundo maior produtor nacional e o principal polo exportador (IBGE, 2007).

O mamão é um fruto climatérico que apresenta rápido amadurecimento pós-colheita, o que o caracteriza como um fruto de grande perecibilidade na fase de pós-colheita e, dessa maneira, o estudo dos fatores que influenciam na taxa respiratória e na liberação de etileno são fundamentais para o planejamento do processo de comercialização (Paull \& Chen, 1983)

O etileno é um fitormônio gasoso importante em todo o desenvolvimento dos frutos, principalmente na fase de amadurecimento. Esse fitormônio está envolvido na aceleração do amadurecimento e senescência de frutos climatéricos, resultando na redução do período de armazenamento desses frutos (Paull et al., 1997). A ação do etileno inicia-se com sua ligação ao seu receptor na célula, desencadeando, em cascata, uma série de reações de fosforilação (Sisler et al., 2006), que sinalizam para a expressão de genes relacionados com o amadurecimento e a senescência dos frutos. Dessa maneira, a interrupção da ligação do etileno ao seu sítio receptor pode retardar sua ação e, consequentemente, o amadurecimento dos frutos (Sisler \& Serek, 2003).

O 1-metilciclopropeno (1-MCP) é um inibidor da ação do etileno que age pela fixação preferencial e irreversível ao receptor do etileno (Blankenship \& Dole, 2003). Essa inibição reduz os efeitos do etileno procedente de fontes internas e externas, aumentando o tempo de armazenamento do fruto na pós-colheita (Lima et al., 2005). O 1-MCP é um produto não tóxico e eficiente, em baixas concentrações, na manutenção da qualidade de frutos (Nanthachai et al., 2007).

O objetivo deste trabalho foi avaliar a resposta de frutos de mamoeiro 'Golden', em diferentes estádios de maturação, à aplicação do 1-MCP.

\section{MATERIAL E MÉTODOS}

Foram utilizados frutos de mamoeiro 'Golden', colhidos no pomar da empresa Caliman Agrícola S/A, da cidade de Linhares - ES. Esta região produtora apresenta temperaturas máximas entre 30 ${ }^{\circ} \mathrm{C}$ e $32{ }^{\circ} \mathrm{C}$ e mínimas entre $15{ }^{\circ} \mathrm{C}$ e $18{ }^{\circ} \mathrm{C}$. Os frutos foram colhidos entre a segunda quinzena de junho e a primeira quinzena de julho e submetidos aos processos de controle de qualidade na casa de embalagem. Posteriormente, os frutos foram transferidos para câmaras a $10^{\circ} \mathrm{C}$, onde o 1-MCP foi aplicado. Os frutos utilizados estavam nos estádios de maturação 0 (verde maduro- fruto com casca $100 \%$ verde); estádio 1 (amadurecendo - a cor amarela não cobre mais de $15 \%$ da superfície da casca), e estádio $2(1 / 4$ maduro - fruto com até $25 \%$ da superfície da casca amarela) (Ritzinger \& Souza, 2000). O 1-MCP foi aplicado na dosagem de $50 \mathrm{~nL} \mathrm{~L}^{-1}$ (Manenoi et al., 2007) a partir do produto comercial com $0,14 \%$ de i.a, com a aplicação realizada em tendas com volume de $1,05 \mathrm{~m}^{3}$, com tempo total de exposição dos frutos ao 1-MCP de 12 horas, conforme recomendação do fabricante - Rohm \& Haas Company. Após este período, os frutos foram armazenados a $25^{\circ} \mathrm{C}$, com avaliações a cada três dias, durante um período de seis dias.

O delineamento experimental adotado foi o inteiramente casualizado, em arranjo fatorial de $3 \times 2 \times 3$, correspondente a três estádios de maturação, dois tratamentos com 1-MCP e três avaliações, com três repetições, sendo cada repetição constituída de um fruto.

Para a quantificação da produção de etileno, foi utilizado um espectrômetro fotoacústico, onde as mudanças de pressão são detectadas por um microfone colocado no interior de um tubo ressonador da célula fotoacústica, através do qual flui a amostra gasosa contendo as moléculas sob investigação. O sinal acústico é produzido pela flutuação periódica de pressão. A amostra (fruto) é colocada dentro de uma câmara onde passa o gás de arraste, ar, monitorada por controladores eletrônicos. Este fluxo passa pelo analisador de gás no infravermelho - URAS, para medição do conteúdo de $\mathrm{CO}_{2}$, e posteriormente por filtros contendo $\mathrm{KOH}$ e $\mathrm{CaCl}_{2}$, para eliminar $\mathrm{CO}_{2}$ e água, respectivamente, no gás analisado. Finalmente, e antes de entrar na célula fotoacústica, o gás passa através de uma armadilha de $\mathrm{N}_{2}$ líquido, evitando a interferência de traços de gases. Após a passagem pela célula fotoacústica, este fluxo é lançado para o ambiente. Assim, é possível monitorar simultaneamente a produção de etileno e de $\mathrm{CO}_{2}$ (Corrêa et al., 2005; Silva et al., 2005).

As medições da coloração do fruto foram realizadas utilizando um colorímetro portátil (Chroma Meter modelo CR-300, Minolta), registrando-se as variáveis de cor, dentro do espaço CIELAB, $L^{*}, a^{*}$, $b^{*}$ e ângulo de cor hue (McGuire, 1992). A firmeza do mesocarpo (FM) e a firmeza do fruto (FF) foram realizadas por meio da resistência à penetração, 
utilizando-se de um penetrômetro de bancada (Fruit Pressure Tester, Italy) com corpo de prova de $8 \mathrm{~mm}$. O teor de sólidos solúveis (SS) foi determinado em refratômetro portátil (Atago N1), e os resultados, expressos em ${ }^{\circ}$ Brix.

A atividade da enzima pectinametilesterase (EC 3.1.1.11) foi avaliada por titulometria dos ésteres produzidos a partir da hidrólise das ramificações metiladas da pectina. A metodologia utilizada foi a descrita por Jen \& Robinson (1984). A unidade de atividade da PME foi considerada como sendo a quantidade de enzima capaz de catalisar a desmetilação da pectina, correspondente a um nmol de grupos carboxílicos por minuto. A enzima poligalacturonase (EC 3.2.1.15) foi extraída segundo o método descrito por Pressey \& Avants (1973). Após a obtenção do extrato enzimático, foram doseados os grupos redutores liberados pela $\mathrm{PG}$, correspondentes aos ácidos galacturônicos, utilizando o procedimento descrito por Nélson (1944). A absorbância das amostras foi lida em espectrofotômetro a $510 \mathrm{~nm}$. A unidade de atividade da PG foi considerada como sendo a quantidade de enzima capaz de catalisar a formação de um nmol de grupos redutores por minuto, nas condições do ensaio. Todo o procedimento para a quantificação da atividade das enzimas PME e PG foi realizado a $25^{\circ} \mathrm{C}$.

Os resultados obtidos foram submetidos à análise de variância (ANOVA), utilizando para tal o programa Genes (Cruz, 2001). As interações significativas nos fatoriais foram desdobradas, sendo as médias comparadas pelo teste de Tukey, a 5\% de probabilidade.

\section{RESULTADOS E DISCUSSÃO}

A aplicação do 1-MCP foi efetiva para a produção de etileno e atividade respiratória dos frutos. Os dados mostram uma redução na produção deste hormônio e do $\mathrm{CO}_{2}$ em frutos nos estádios $0 ; 1$ e 2 de maturação, tratados com 1-MCP. Os frutos nos estádios 0 e 1, mesmo não tratados com o 1-MCP, também apresentaram baixa produção de etileno (Figura 1). Os resultados mostram que a redução na emissão de etileno e de $\mathrm{CO}_{2}$ foi maior nos frutos em estádio 0 de maturação, tratados com o 1-MCP. Em média (considerando todo o período de armazenamento), a redução na taxa respiratória foi de 44,7; 36,3 e 35,2 \% para frutos nos estádios $0 ; 1$ e 2 de maturação, respectivamente. Para a emissão de etileno, a redução foi 79,3; 26,0 e 59,6\% em frutos nos estádios $0 ; 1$ e 2 de maturação, respectivamente, tratados com 1-MCP. Resultados equivalentes foram obtidos por Manenoi et al. (2007), que observaram, também, redução na produção de etileno em frutos de mamão no estádio 1 de maturação, quando tratados com 1-MCP e armazenados à temperatura ambiente.

Os resultados mostram que não somente a concentração do hormônio, mas também a sensibilidade do tecido ao etileno é determinante para as respostas celulares, estando isto relacionado ao estádio de desenvolvimento dos frutos (Trewavas, 1982). A ação do 1-MCP é mediada através da inibição da percepção do etileno pelo tecido vegetal, pela interatividade com o receptor e competição com o etileno pelo sítio de ligação (Sisler \& Serek, 2003), o que pode estar relacionado ao estádio de maturação do fruto.

A efetiva ação do 1-MCP em frutos armazenados à temperatura ambiente está relacionada com o estádio de maturação em que os frutos são tratados. Trabalhos têm mostrado respostas menos efetivas desse inibidor da ação do etileno em frutos em estádios de maturação mais avançados. Isto foi observado em tomates, onde quanto mais avançada a fase de desenvolvimento do fruto, menor o tempo de inibição da produção de etileno (Wills \& Ku, 2002), demonstrando que o estádio de maturação do fruto interfere na resposta efetiva do 1-MCP sobre a produção de etileno.

A taxa respiratória observada neste trabalho foi reduzida em frutos tratados com 1-MCP, independentemente do estádio de maturação avaliado. Os resultados mostram que a diferença na atividade respiratória entre frutos tratados e não tratados com o 1-MCP foi maior que a diferença observada na emissão de etileno, entre esses mesmos tratamentos, nos frutos em estádio 1 de maturação. Já para frutos nos estádios 0 e 2 de maturação, a redução na emissão de etileno foi maior que a redução na taxa respiratória nos frutos tratados com o 1-MCP (Figura 1).

$\mathrm{O}$ tratamento com 1-MCP reduziu significativamente $(\mathrm{P}<0,05)$ a perda de coloração verde dos frutos, principalmente nos estádios 0 e 1 de maturação, afetando os parâmetros de cor $a^{*}, b^{*} \mathrm{e}$ ângulo hue (Tabela 1). No estádio 0 , os parâmetros $a^{*}, b^{*}$ e $L^{*}$ indicaram uma tendência de maior retenção de coloração verde nestes frutos. O ângulo de cor hue manteve-se maior em frutos tratados com 1-MCP, demonstrando que houve maior retenção da coloração verde em frutos no estádio 0 de maturação (Tabela 1). Nos estádios 1 e 2 de maturação, houve tendência de redução na perda de coloração verde nos frutos tratados com $1-\mathrm{MCP}$ até o $3^{\circ}$ dia de prateleira. Porém, do $3^{\circ}$ ao $6^{\circ}$ dia, os parâmetros $a^{*}$ e $b^{*}$ apresentaram valores com tendência de perda de coloração verde, assim como redução nos valores do ângulo hue, indicando intenso processo de ama- 
relecimento da casca.

A retenção da coloração verde em frutos de mamoeiro tratados com 1-MCP também foi verificada por Jacomino et al., (2002) e por Manenoi et al., (2007) como também em outras frutas, como banana (Lima et al., 2005), abacate (Fan et al., 2000) e manga (Hofman et al., 2001). A perda de coloração verde do fruto está ligada à quebra da estrutura da molécula de clorofila, envolvendo, principalmente, a atividade da enzima clorofilase, que é modulada pelo etileno (Yamauchi et al., 1997; Mendonça et al., 2003). Assim, a redução na produção de etileno verificada em frutos tratados com 1-MCP (Figura 1) pode ter influência direta na redução da perda de coloração verde do fruto. Há poucos trabalhos na literatura a respeito dos efeitos do $1-\mathrm{MCP}$ sobre o metabolismo de pigmentos, entre os quais, Hershkovitz et al., (2005) e Win et al., (2006) verificaram redução na atividade da clorofilase em frutos tratados com 1-MCP.

Nos frutos nos estádios $0 ; 1$ e 2 de maturação e tratados com 1-MCP, verifica-se redução na perda da FM e FF, principalmente nos 3 primeiros dias de armazenamento (Tabela 2). Os frutos no estádio 0 de maturação apresentaram, no $6^{\circ}$ dia de armazenamento, valores de FM e FF de 109,27 N e $30,7 \mathrm{~N}$, respectivamente, o que representa valores excessivamente altos para este parâmetro (Tabela 2). Nos frutos que se encontram no estádio 2 de maturação, os resultados mostram que a perda da $\mathrm{FM} \mathrm{e}$ FF também foi reduzida com a aplicação do 1-MCP, demonstrando um efeito positivo deste inibidor na ação do etileno, mesmo em estádio de maturação mais avançado (Tabela 2). A retenção da FM e da FF também foi verificada por Manenoi et al. (2007) em frutos de mamão, bem como por Hershkovitz et al., (2005) em frutos de três cultivares de abacate. Sabe-se que a perda na FM tem estreita relação com a atividade de enzimas pectinolíticas, que estão envolvidas na degradação da parede celular (Brummell \& Harpster, 2001), cuja atividade é modulada pela ação do etileno (Paull \& Chen, 1983).

Os resultados mostram que não houve alterações significativas no teor de sólidos solúveis (SS) entre frutos tratados e não tratados com 1-MCP, independentemente do estádio de maturação avaliado (Tabela 2). Foram observadas alterações no teor de SS ao longo do período de armazenamento, entretanto essas diferenças não comprometeram a qualidade dos frutos, uma vez que o teor de SS foi sempre superior a $11,5^{\circ} \mathrm{Brix}$, valor mínimo segundo Almeida (2003), para os frutos atingirem qualidade para exportação. Este padrão de resposta também foi observado por Manenoi et al., (2007) e por Jacomino et al., (2002), que relataram não ter encontrado influência do 1-MCP no teor de SS, quando aplicado em mamão no estádio de maturação verde e maduro. De modo geral, as respostas do 1-MCP sobre o teor de SS em mamão podem ocorrer de maneira distinta o que, de certo modo, vai depender da cultivar, do estádio de maturação dos frutos e do tipo de armazenamento (Watkins et al., 2000).

A atividade das enzimas PME e PG apresentou tendências distintas durante os seis dias de armazenamento. Enquanto a PME mostrou maior atividade no terceiro dia, em frutos nos estádios 0 e 1 de maturação, a PG apresentou tendência crescente, atingindo maior atividade ao final de seis dias (Figura 2). A aplicação do 1-MCP reduziu a atividade das enzimas PME e $\mathrm{PG}$, independentemente do estádio de maturação em que os frutos foram tratados, ainda que esta diferença tenha sido mais expressiva nos frutos do estádio 0 de maturação. Estes resultados reforçam as informações que já se conhece a respeito da atuação destas enzimas no processo de amolecimento da polpa, visto que, nos três estádios de maturação, houve retenção significativa da FM com a redução na produção do etileno. Segundo Paull \& Chen (1983), a atividade da PME em mamão aumenta gradualmente durante o amadurecimento, alcançando um máximo após o climatério. A atividade desta enzima pode ser detectada mesmo antes do amadurecimento dos frutos (Paull et al., 1997). Tendo em vista a forma de atuação destas enzimas (Carpita \& McCann, 2000), é de se esperar que a atividade da PME deva preceder a atividade da PG, na medida em que os grupos metil esterificados são removidos dos resíduos de galacturosil da matriz de polissacarídeos da pectina (Assis et al., 2001).

A enzima PME participa diretamente na etapa inicial do processo de perda de firmeza da polpa do mamão, apresentando um aumento contínuo com a solubilização da pectina, sugerindo que solubilização e a despolimerização são eventos independentes e que a PG atuaria somente na solubilização da pectina, sem efeito no amolecimento da polpa (Manrique \& Lajolo, 2004).

Outras enzimas, como a endoxilanase (Chen $\&$ Paull, 2003) e a celulase (Paull \& Chen, 1983), também têm papel importante sobre o processo de amaciamento da polpa do mamão. Porém, tendo em vista que mais de $50 \%$ dos constituintes da parede celular de frutos são compostos da fração pectina (Carpita \& McCann, 2000), a modulação da atividade da PME e PG através do controle da ação do etileno é determinante para a qualidade do mamão. 
TABELA 1- Efeito do 1-MCP sobre os parâmetros de cor $L^{*}, a^{*}, b^{*}$ e ângulo de cor hue $\left(\mathrm{h}^{\circ}\right)$ em frutos de mamoeiro 'Golden' nos estádios $0 ; 1$ e 2 de maturação. Os frutos foram colhidos de uma mesma área de plantio e armazenados a $25^{\circ} \mathrm{C}$ por 6 dias.

\begin{tabular}{|c|c|c|c|c|c|c|c|c|c|}
\hline \multirow[b]{3}{*}{ Maturação } & \multirow{3}{*}{$\begin{array}{l}\text { Período } \\
\text { de } \\
\text { armaze- } \\
\text { namento }\end{array}$} & \multicolumn{8}{|c|}{ Parâmetros de cor } \\
\hline & & \multicolumn{2}{|c|}{$L^{*}$} & \multicolumn{2}{|c|}{$a^{*}$} & \multicolumn{2}{|c|}{$b^{*}$} & \multicolumn{2}{|c|}{ hue } \\
\hline & & $\begin{array}{c}\text { Com } \\
\text { 1-MCP }\end{array}$ & $\begin{array}{c}\text { Sem } \\
\text { 1-MCP }\end{array}$ & $\begin{array}{c}\text { Com } \\
\text { 1-MCP }\end{array}$ & $\begin{array}{c}\text { Sem } \\
1-\mathrm{MCP}\end{array}$ & $\begin{array}{c}\text { Com } \\
\text { 1-MCP }\end{array}$ & $\begin{array}{c}\text { Sem } \\
\text { 1-MCP }\end{array}$ & $\begin{array}{c}\text { Com } \\
\text { 1-MCP }\end{array}$ & $\begin{array}{c}\text { Sem } \\
\text { 1-MCP }\end{array}$ \\
\hline Estádio 0 & $\begin{array}{l}0 \\
3 \\
6\end{array}$ & $\begin{array}{l}55,9 \mathrm{Aa} \\
64,4 \mathrm{Ab} \\
70,8 \mathrm{Ac}\end{array}$ & $\begin{array}{l}59,0 \mathrm{Ba} \\
73,3 \mathrm{Bb} \\
73,0 \mathrm{Bb}\end{array}$ & $\begin{array}{c}-18,3 \mathrm{Aa} \\
-11,7 \mathrm{Ab} \\
-2,3 \mathrm{Ac}\end{array}$ & $\begin{array}{c}-14,3 \mathrm{Ba} \\
5,5 \mathrm{Bb} \\
9,3 \mathrm{Bc}\end{array}$ & $\begin{array}{l}40,0 \mathrm{Aa} \\
48,9 \mathrm{Ab} \\
58,9 \mathrm{Ac}\end{array}$ & $\begin{array}{l}31,0 \mathrm{Ba} \\
62,3 \mathrm{Bb} \\
61,0 \mathrm{Ab}\end{array}$ & $\begin{array}{c}114,5 \mathrm{Aa} \\
103,5 \mathrm{Ab} \\
92,3 \mathrm{Ac}\end{array}$ & $\begin{array}{l}111,5 \mathrm{Ba} \\
85,0 \mathrm{Bb} \\
81,3 \mathrm{Bc}\end{array}$ \\
\hline Estádio 1 & $\begin{array}{l}0 \\
3 \\
6\end{array}$ & $\begin{array}{l}61,3 \mathrm{Aa} \\
68,4 \mathrm{Ab} \\
73,6 \mathrm{Ac}\end{array}$ & $\begin{array}{l}62,0 \mathrm{Aa} \\
71,1 \mathrm{Bb} \\
69,0 \mathrm{Bc}\end{array}$ & $\begin{array}{c}-14,9 \mathrm{Aa} \\
-6,1 \mathrm{Ab} \\
6,9 \mathrm{Ac}\end{array}$ & $\begin{array}{c}-16,1 \mathrm{Ba} \\
10,8 \mathrm{Bb} \\
13,6 \mathrm{Bc}\end{array}$ & $\begin{array}{l}44,3 \mathrm{Aa} \\
57,5 \mathrm{Ab} \\
61,6 \mathrm{Ac}\end{array}$ & $\begin{array}{l}43,0 \mathrm{Aa} \\
58,6 \mathrm{Ab} \\
60,1 \mathrm{Ab}\end{array}$ & $\begin{array}{l}108,9 \mathrm{Ba} \\
94,6 \mathrm{Ab} \\
83,6 \mathrm{Ac}\end{array}$ & $\begin{array}{c}110,3 \mathrm{Aa} \\
79,6 \mathrm{Bb} \\
77,4 \mathrm{Bc}\end{array}$ \\
\hline Estádio 2 & $\begin{array}{l}0 \\
3 \\
6\end{array}$ & $\begin{array}{l}62,7 \mathrm{Aa} \\
68,8 \mathrm{Ab} \\
72,6 \mathrm{Ac}\end{array}$ & $\begin{array}{l}61,8 \mathrm{Aa} \\
72,3 \mathrm{Bb} \\
64,4 \mathrm{Bc}\end{array}$ & $\begin{array}{c}-10,8 \mathrm{Aa} \\
-6,0 \mathrm{Ab} \\
6,6 \mathrm{Ac}\end{array}$ & $\begin{array}{c}-13,8 \mathrm{Ba} \\
11,1 \mathrm{Bb} \\
5,7 \mathrm{Bc}\end{array}$ & $\begin{array}{l}45,7 \mathrm{Aa} \\
58,8 \mathrm{Ab} \\
63,0 \mathrm{Ac}\end{array}$ & $\begin{array}{l}47,6 \mathrm{Aa} \\
62,3 \mathrm{Ab} \\
61,8 \mathrm{Ab}\end{array}$ & $\begin{array}{l}103,7 \mathrm{Ba} \\
93,8 \mathrm{Ab} \\
84,1 \mathrm{Ac}\end{array}$ & $\begin{array}{l}106,3 \mathrm{Aa} \\
79,9 \mathrm{Bb} \\
75,8 \mathrm{Bc}\end{array}$ \\
\hline
\end{tabular}

Médias seguidas de mesma letra maiúscula na linha e minúscula na coluna não diferem entre si, pelo teste de Tukey, a 5\% de probabilidade.

TABELA 2 - Firmeza do fruto (FF), firmeza do mesocarpo (FM) e teor de sólidos solúveis (SS) em frutos de mamoeiro 'Golden' tratados com 1-MCP em diferentes estádios de maturação. Os frutos foram colhidos de uma mesma área de plantio e armazenados a $25^{\circ} \mathrm{C}$ por 6 dias.

\begin{tabular}{|c|c|c|c|c|c|c|c|}
\hline \multirow[b]{2}{*}{ Maturação } & \multirow[b]{2}{*}{$\begin{array}{c}\text { Período de } \\
\text { armzenamento }\end{array}$} & \multicolumn{2}{|c|}{$\mathrm{FF}(\mathrm{N})$} & \multicolumn{2}{|c|}{$\mathrm{FM}(\mathrm{N})$} & \multicolumn{2}{|c|}{$\mathrm{SS}^{\circ} \mathrm{Brix}$} \\
\hline & & $\begin{array}{c}\text { Com } \\
1-\mathrm{MCP}\end{array}$ & $\begin{array}{c}\text { Sem } \\
1-\mathrm{MCP}\end{array}$ & $\begin{array}{c}\text { Com } \\
1-\mathrm{MCP}\end{array}$ & $\begin{array}{c}\text { Sem } \\
1-\mathrm{MCP}\end{array}$ & $\begin{array}{c}\text { Com } \\
1-\mathrm{MCP}\end{array}$ & $\begin{array}{c}\text { Sem } \\
1-\mathrm{MCP}\end{array}$ \\
\hline Estádio 0 & $\begin{array}{l}0 \\
3 \\
6\end{array}$ & $\begin{array}{l}158,7 \mathrm{Aa} \\
163,6 \mathrm{Aa} \\
109,3 \mathrm{Ab}\end{array}$ & $\begin{array}{c}131,6 \mathrm{Ba} \\
19,8 \mathrm{Bb} \\
18,7 \mathrm{Bb}\end{array}$ & $\begin{array}{l}74,4 \mathrm{Aa} \\
45,6 \mathrm{Ab} \\
30,7 \mathrm{Ac}\end{array}$ & $\begin{array}{c}60,2 \mathrm{Ba} \\
3,8 \mathrm{Bb} \\
2,8 \mathrm{Bb}\end{array}$ & $\begin{array}{l}12,2 \mathrm{Ab} \\
13,2 \mathrm{Aa} \\
13,6 \mathrm{Aa}\end{array}$ & $\begin{array}{l}12,3 \mathrm{Ab} \\
13,6 \mathrm{Aa} \\
13,4 \mathrm{Aa}\end{array}$ \\
\hline Estádio 1 & $\begin{array}{l}0 \\
3 \\
6\end{array}$ & $\begin{array}{c}176,2 \mathrm{Aa} \\
161,3 \mathrm{Aa} \\
76,9 \mathrm{Ab}\end{array}$ & $\begin{array}{l}88,2 \mathrm{Ba} \\
17,2 \mathrm{Bb} \\
15,3 \mathrm{Bb}\end{array}$ & $\begin{array}{l}48,2 \mathrm{Aa} \\
41,9 \mathrm{Aa} \\
10,2 \mathrm{Ab}\end{array}$ & $\begin{array}{c}42,0 \mathrm{Ba} \\
3,4 \mathrm{Bb} \\
3,2 \mathrm{Bb}\end{array}$ & $\begin{array}{l}12,8 \mathrm{Ab} \\
13,4 \mathrm{Aa} \\
14,2 \mathrm{Aa}\end{array}$ & $\begin{array}{l}13,4 \mathrm{Ab} \\
13,8 \mathrm{Aa} \\
14,2 \mathrm{Aa}\end{array}$ \\
\hline Estádio 2 & $\begin{array}{l}0 \\
3 \\
6\end{array}$ & $\begin{array}{l}161,6 \mathrm{Aa} \\
177,9 \mathrm{Aa} \\
108,5 \mathrm{Ab}\end{array}$ & $\begin{array}{c}104,1 \mathrm{Ba} \\
12,1 \mathrm{Bb} \\
10,2 \mathrm{Bb}\end{array}$ & $\begin{array}{l}69,2 \mathrm{Aa} \\
51,8 \mathrm{Ab} \\
11,4 \mathrm{Ac}\end{array}$ & $\begin{array}{l}8,5 \mathrm{Ba} \\
3,5 \mathrm{Ba} \\
2,8 \mathrm{Ba}\end{array}$ & $\begin{array}{l}13,6 \mathrm{Ab} \\
14,2 \mathrm{Aa} \\
13,6 \mathrm{Ab}\end{array}$ & $\begin{array}{l}13,6 \mathrm{Ab} \\
14,0 \mathrm{Aa} \\
13,5 \mathrm{Ab}\end{array}$ \\
\hline
\end{tabular}

Médias seguidas de mesma letra maiúscula na linha e minúscula na coluna não diferem entre si, pelo teste de Tukey, a 5\% de probabilidade.

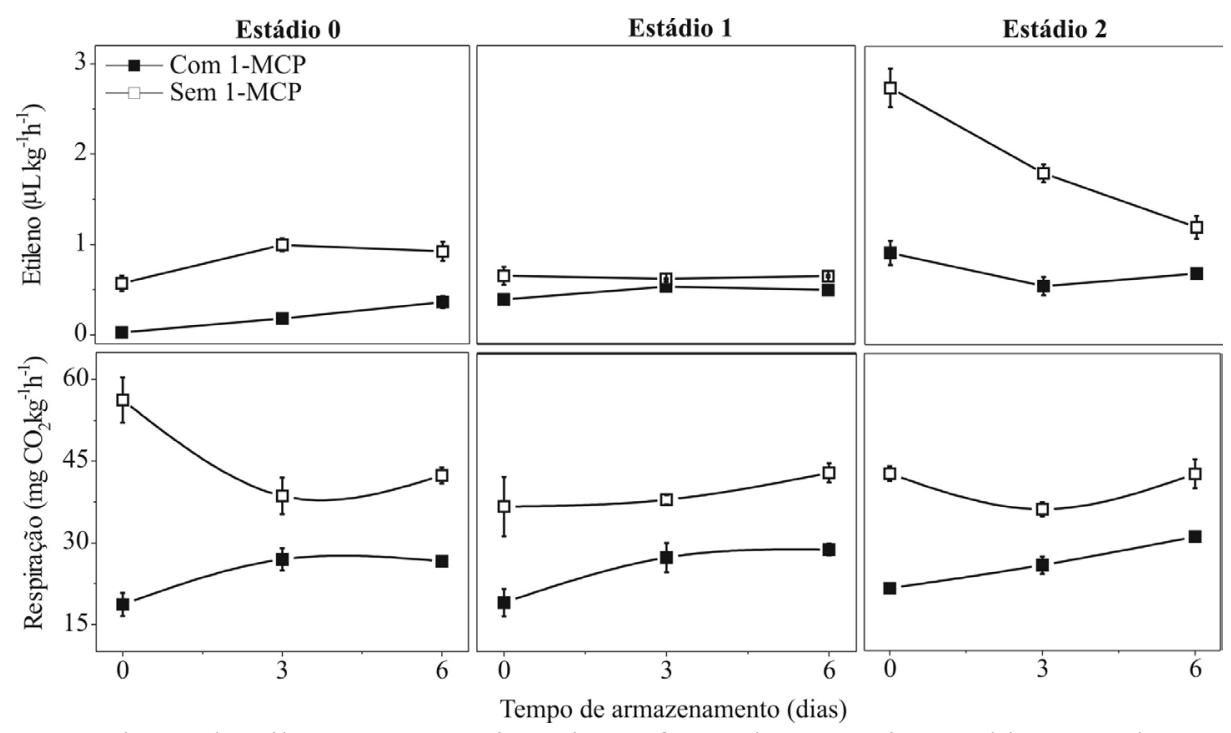

FIGURA 1 - Produção de etileno e taxa respiratória em frutos de mamoeiro 'Golden' tratados com 1-MCP em diferentes estádios de maturação. Os frutos foram colhidos de uma mesma área de plantio e armazenados a $25^{\circ} \mathrm{C}$ por 6 dias. Barras verticais indicam o erro-padrão da média $(n=3)$. 


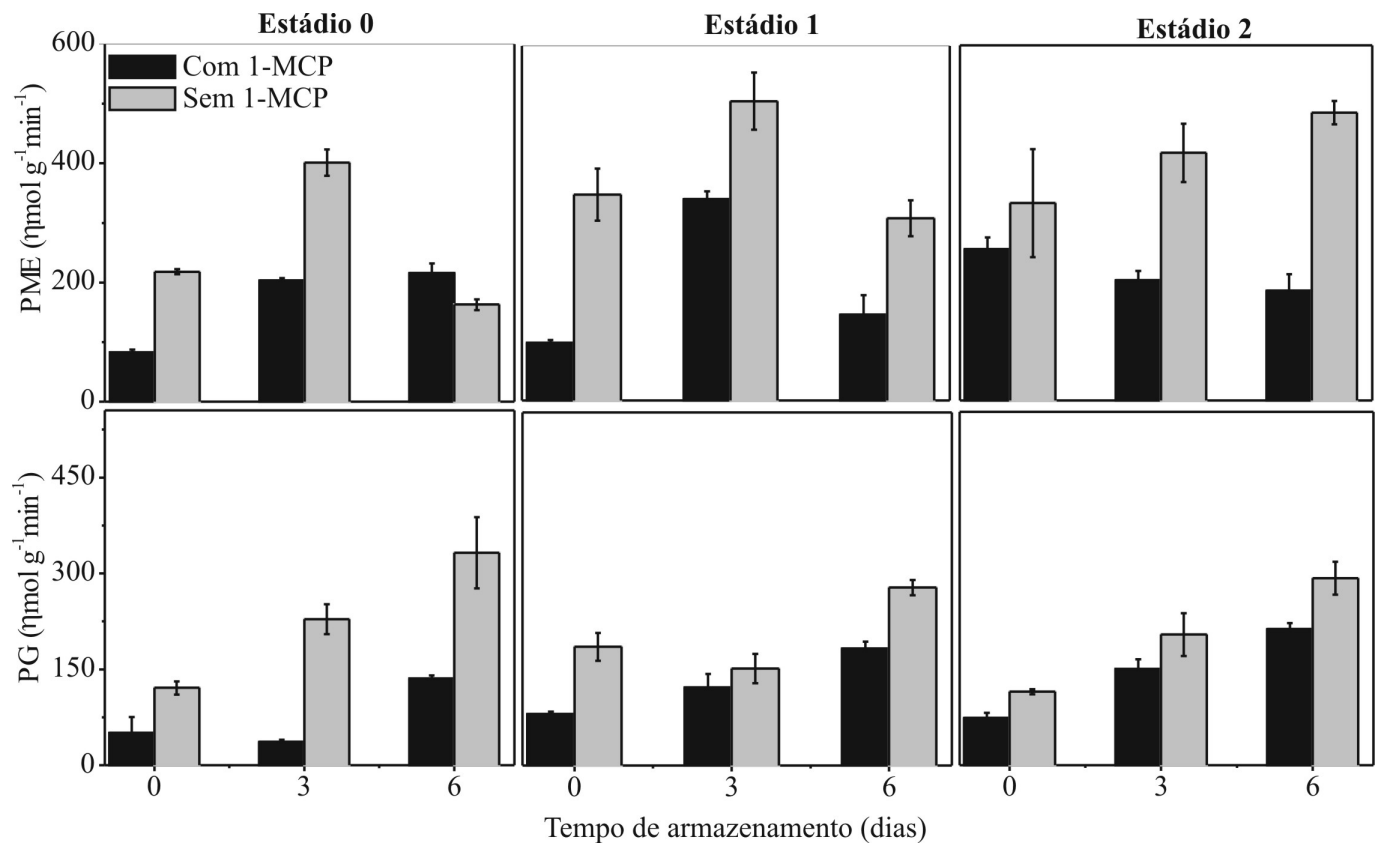

FIGURA 2 - Atividade das enzimas pectinametilesterase (PME) e poligalacturonase (PG) em frutos de mamoeiro 'Golden' tratados com 1-MCP em diferentes estádios de maturação. Os frutos foram colhidos de uma mesma área de plantio e armazenados a $25^{\circ} \mathrm{C}$ por 6 dias. Barras verticais indicam o erro-padrão da média $(\mathrm{n}=3)$.

\section{CONCLUSÃO}

A aplicação do 1-MCP retardou o amadurecimento do mamão 'Golden' no período de póscolheita, na medida em que proporcionou redução na produção de etileno e na taxa respiratória. A perda de coloração verde da casca foi reduzida nos frutos tratados com 1-MCP nos estádios 0 e 1 de maturação. A atividade das enzimas PME e PG foi reduzida e, como consequência, retardou a perda de firmeza da polpa dos frutos. A enzima PME apresentou maior incremento na atividade que a $\mathrm{PG}$, nos três primeiros dias de armazenamento, indicando a importância da PME no amolecimento da polpa dos frutos de mamoeiro nas etapas iniciais de comercialização.

\section{AGRADECIMENTO}

Os autores expressam seus agradecimentos à empresa Caliman Agrícola S/A, pelo suporte logístico; ao FINEP, através do projeto Frutimamão, pelo suporte financeiro; à CAPES e ao $\mathrm{CNPq}$, pela concessão de bolsa de pesquisa e, à empresa Rhom \& Hass, pelo fornecimento do 1-MCP para a realização deste trabalho.

\section{REFERÊNCIAS}

ALMEIDA, M.E.M. Processamento industrial da polpa do mamão. In: MARTINS, D.S. (Ed.). Papaya Brasil: qualidade do mamão para o mercado interno. Vitória-ES: Incaper. 293p. 2003.

ASSIS, S.A.; LIMA, D.C.; OLIVEIRA, O.M.M.F. Activity of pectin methylesterase, pectin content and vitamin $\mathrm{C}$ in acerola fruit at various stages of fruit development. Food Chemistry, Berkshire, v.74, p.133-137, 2001.

BLANKENSHIP, S.M.; DOLE, J.M. 1-Methylcyclopropene: a review. Postharvest Biology and Technology, Amsterdam, v.28, p.1-25, 2003.

BRUMMELL, D.A.; HARPSTER, M.H. Cell wall metabolism in fruit softening and quality and its manipulation in transgenic plants. Plant Molecular Biology, Dordrecht, v.77, p.311-340, 2001.

CARPITA, N.; MCCANN, M. THE CELL WALL. IN: BUCHANAN, B.; GRUISSEM, W.; JONES, R. (Eds.). Biochemistry \& molecular biology of plants, Maryland: The American Society of Plant Biologists, 2000. p.52-108. 
CHEN, N.J.; PAULL, R.E. Endoxylanase expressed during papaya fruit ripening: purification, cloning and characterization. Functional Plant Biology, Collingwood, v.30, n.4, p.433-441, 2003.

CORRÊA, S.F.; FILHO, M.B.; DA SILVA, M.G.; OLIVEIRA, J.G.; AROUCHA, E.M.M.; SILVA, R.F.; PEREIRA, M.G.; VARGAS, H. Effect of the potassium permanganate during papaya fruit ripening: Ethylene production. Journal of Physique IV, Paris, v.25, p.869-871, 2005.

CRUZ, C.D. Programa Genes (versão Windows): aplicativo computacional em Genética e Estatística. Viçosa: Editora UFV, 2001. p.648.

FAN, X.; ARGENTA, L.; MATTHEIS, J.P. Inhibition of ethylene action by 1 -methylcyclopropene prolongs storage life of apricots. Postharvest Biology and Technology, Amsterdam, v.20, p.135-142, 2000.

HERSHKOVITZ, V.; SAGUY, S.I.; PESIS, E. Postharvest application of 1-MCP to improve the quality of various avocado cultivars. Postharvest Biology and Technology, Amsterdam, v.37, p.252264, 2005.

HOFMAN, P.J.; JOBIN-DÉCOR, M.; MEIBURG, G.F.; MACNISH, A.J.; JOYCE, D.C. Ripening and quality responses of avocado, custard apple, mango and papaya fruit to 1-methylcyclopropene. Australian Journal of Agricultural, Victoria, v.41, p.567-572, 2001 .

IBGE - Instituto Brasileiro de Geografia e Estatística. Produção e exportação de mamão no Estado do Espírito Santo. 2007. Disponível em: <www.ibge. gov.com.br>. Acesso em: 10 nov. 2007.

JACOMINO, A.J.; KLUGE, R.A.; BRACKMAN, A.; CASTRO, P.R. DE C. Amadurecimento e senescência de mamão com 1-Metilciclopropeno. Scientia Agrícola, Piracicaba, v.59, n.2, p.303-308, 2002

JEN, J.J.; ROBINSON, M.L.P. Pectolitic enzymes in sweet bell peppers (Capsicum annum L.). Journal of food Science, Chicago, v.49, p.1085-1087, 1984.

LIMA, L.C.; COSTA, S.M.; DIAS, M.S.C.; MARTINS, R.N.; RIBEIRO JÚNIOR, P.M. Controle do amadurecimento de banana 'Prata-Anã' armazenada sob refrigeração e atmosfera modificada passiva com o uso do 1-Metilciclopropeno. Ciência e Agrotecnologia, Lavras, v.29, p.476-480, 2005.

MANENOI, A.; BAYOGAN, E.R.V.; THUMDEE, S.; PAULL, R.E. Utility of 1-methylcyclopropene as a papaya postharvest treatment. Postharvest Biology and Technology, Amsterdam, v.44, p.55-62, 2007.

MANRIQUE, G. D.; LAJOLO, F.M. Cell-Wall polysaccharide modification during postharvest ripening of papaya fruit (Carica papaya L.). Postharvest Biology and Technology, Amsterdam, v.33, p.1126, 2004.

MARTINS, D.S.; COSTA, A. F. A cultura do mamoeiro (Carica papaya L.): tecnologias de produção. Vitória: Incaper, 2003. p.497.

MCGUIRE, R.G. Reporting of objective color measurements. HortScience, Alexandria, v.27, p.12541255, 1992.

MENDONÇA, K.; JACOMINO, A.P.; MELHEM, T.X.; KLUGE, R.A. Concentração de etileno e tempo de exposição para desverdecimento de limão 'Siciliano'. Brazilian Journal of Food Technology, Campinas, v.6, n.2, p.179-183, 2003.

NANTHACHAI, N.N.; RATANACHINAKRON, B.; KOSITTRAKUN, M.; BEAUDRY, R.M. Absorption of 1-MCP by fresh produce. Postharvest Biology and Technology, Amsterdam, v.43, p.291297, 2007.

NELSON, N. A. A photometric adaptation of Somogy method for determination of glucose. Journal of Biological Chemistry, Baltimore, v.135, n.1, p.136-175, 1944.

PAULL, R.E.; CHEN, N.J. Postharvest variation in cell wall-degradation enzymes of papaya (Carica papaya L.) during fruit ripening. Plant Physiology, Washington, v.72, p.382-385, 1983.

PAULL, R.E.; NISHIJIMA, W.; REYES, M.; CAVALETTO, C. Postharvest handling and losses during marketing of papaya (Carica papaya L.). Postharvest Biology and Technology, Amsterdam, v.11, p.165-179, 1997.

PRESSEY, R.; AVANTS, J.K. Separation and characterization of the exopolygalacturonase and endopolygalacturonase from peaches. Plant Physiology, Washington, v.52, p.252-256, 1973. 
RITZINGER, C.H.S.P.; SOUZA, J.S. Mamão: fitossanidade. Cruz das Almas: Embrapa Mandioca e Fruticultura. 2000. p.91. Comunicação para transferência de Tecnologia

SILVA, M.G.; OLIVEIRA, J.G.; VITÓRIA, A.P.; CORRÊA, S.F.; PEREIRA, M.G.; CAMPOSTRINI, E.; SANTOS, E.O.; CAVALLI, A.; VARGAS, $\mathrm{H}$. Correlation between ethylene emission and skin colour changes during papaya (Carica papaya L.) fruit ripening. Journal of Physique IV, Paris, v.125, p.877-879, 2005.

SISLER, E.C.; GRICHKO, V.P.; SEREK, M. Interaction of ethylene and other compounds with the ethylene receptor: agonists and antagonists. In.: KHAN, N.A. (Ed.). Ethylene action en plants. Berlim: Springer, 2006. 206p.

SISLER, E.C., SEREK, M. Compounds interacting with the ethylene receptor in plants. Acta Horticulturae, Leuven v.5, p.473-480, 2003.

SISLER, E.C.; GRICHKO, V.P.; SEREK, M. Interaction of ethylene and other compounds with the ethylene receptor: agonists and antagonists. In.: KHAN, N.A. (Ed.). Ethylene action en plants. Berlim: Springer, 2006. 206p.

TREWAVAS, A.J. Growth substance sensitivity: the limiting factor in plant development. Physiology Plantarum, Edinburgh, v.55, p.60-72, 1982.
WATKINS, C.B.; NOCK, J.F.; WHITAKER, B.D. Responses of early, mid and late season apple cultivars to postharvest application of 1-methylcyclopropene under air and controlled atmosphere storage conditions. Postharvest Biology and Technology, Amsterdam, v.19, p.17-32, 2000.

WILLS, R.B.H.; KU, V.V.V. Use of 1-MCP to extend the time to ripen of green tomatoes and postharvest life of ripe tomatoes. Postharvest Biology and Technology, Amsterdam, v.26, n.1, p.85-90, 2002.

WIN, T.O.; SRILAONG, V.; HEYES, J.; KYU, K.L.; KANLAYANARAT, S. Effects of different concentrations of 1-MCP on the yellowing of West Indian lime (Citrus aurantifolia, Swingle) fruit. Postharvest Biology and Technology, Amsterdam, v.42, n.1, p.23-30, 2006.

YAMAUCHI, N.; AKIYAMA, Y.; KAKO, S.; HASHINAGA, F. Chlorophyll degradation in Wase satsuma mandarin (Citrus unshiu Marc.) fruit with on-tree maturation and ethylene treatment. Scientia Horticulturae, Amsterdam, v.71, n.1, p.35-42, 1997. 